\title{
Phosphorus Nanorods-Two Allotropic Modifications of a Long-Known Element
}

\author{
Arno Pfitzner,* Michael F. Bräu, Josef Zweck, \\ Gunther Brunklaus, and Hellmut Eckert* \\ Dedicated to Professor H. G. von Schnering
}

Elemental phosphorus has been known for about 350 years. As a result of huge scientific interest, numerous textbooks are filled with information about this element, its different allotropes, and its compounds. ${ }^{[1]}$ Like boron and carbon, the element features tremendous structural variability, resulting in great diversity of physical properties and chemical reactivity: White phosphorus, $\mathrm{P}_{4}$, forms three crystal struc-

[*] Prof. Dr. A. Pfitzner, M. F. Bräu

Institut für Anorganische Chemie

Universität Regensburg, 93040 Regensburg (Germany)

Fax: (+49) 941-943-4983

E-mail: arno.pfitzner@chemie.uni-regensburg.de

Dr. G. Brunklaus, Prof. H. Eckert

Institut für Physikalische Chemie

Westfälische Wilhelms-Universität, 48149 Münster (Germany)

Fax: (+49) 251-832-9159

E-mail: eckerth@uni-muenster.de

Prof. Dr. J. Zweck

Institut für Experimentelle und Angewandte Physik

Universität Regensburg, 93040 Regensburg (Germany) 
tures,${ }^{[2]}$ including a plastic phase at room temperature, and is highly reactive with air. Violet (Hittorf's) phosphorus forms layers of chain polymers ${ }^{[3]}$ and is less reactive, whereas black phosphorus, the conducting high-pressure modification, ${ }^{[4]}$ has full $2 \mathrm{D}$ connectivity and is, comparably, chemically inert. Theoretical investigations by Häser and Böcker showed that alternative molecular and polymeric structures can be expected for the pure element. ${ }^{[5]}$ However, due to difficulties in obtaining crystalline material no more allotropic forms, such as red phosphorus have yet been structurally wellcharacterized.

Recent research has shown that copper halides can be used as a unique synthetic tool towards the formation of compounds with new phosphorus-based architectures, such as low-charged phosphorus polyanions and phosphorus chalcogenide cage molecules. ${ }^{[6-11]}$ Furthermore, polymeric phosphorus strands are readily formed as their copper iodide adducts by treating stoichiometric mixtures of $\mathrm{CuX}(\mathrm{X}=\mathrm{Br}, \mathrm{I})$ with elemental $\mathrm{P}$. Compounds of this kind include two different ${ }_{\infty}^{1}\left[\mathrm{P}_{12}\right]$ polymers in $(\mathrm{CuI})_{8} \mathrm{P}_{12}{ }^{[12]}$ and in $(\mathrm{CuI})_{3} \mathrm{P}_{12},{ }^{[13]}$ respectively, and a ${ }_{\infty}^{1}\left[\mathrm{P}_{14}\right]$ polymer in $(\mathrm{CuI})_{2} \mathrm{P}_{14 \cdot}{ }^{[14]}$ The separation of the pure phosphorus strands from the copper halide matrix represents an intriguing chemical challenge and should help to verify the theoretical investigations. Herein, we report the isolation and characterization of the ${ }_{\infty}^{1}\left[\mathrm{P}_{12}\right]$ polymers which are present in $(\mathrm{CuI})_{8} \mathrm{P}_{12}-{ }_{\infty}^{1}[\mathrm{P} 8] \mathrm{P} 4(4)\left[(\mathbf{1})\right.$ - and in $(\mathrm{CuI})_{3} \mathrm{P}_{12}$ ${ }_{\infty}^{1}[\mathrm{P} 10] \mathrm{P} 2\left[(\mathbf{2}\right.$; Figure 1$)$-by a low-temperature route. ${ }^{[15]}$

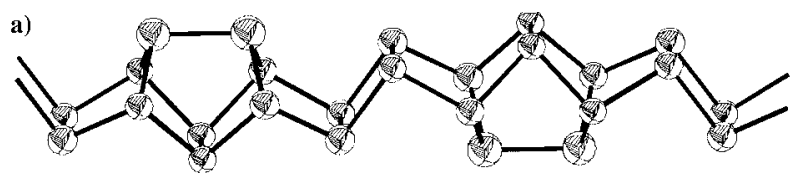

b)

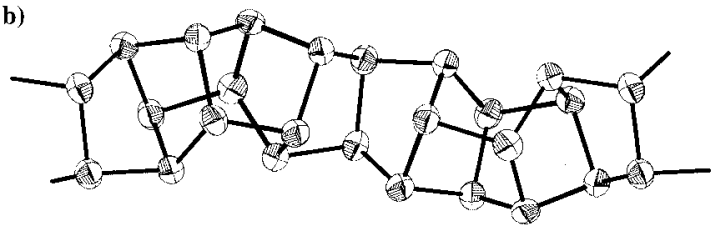

Figure 1. Structure of a) $\mathbf{1}$ and b) $\mathbf{2}$ as observed in their adducts to copper iodide. Data for 1 are taken from reference [12].

The copper iodide adducts were obtained by a typical high-temperature synthesis and the resulting crystalline materials were subsequently treated with an aqueous solution of potassium cyanide at room temperature. For both crystalline $(\mathrm{CuI})_{8} \mathrm{P}_{12}$ and crystalline $(\mathrm{CuI})_{3} \mathrm{P}_{12}$, the surfaces of the crystals were destroyed and dark-red/brown fibrous products were obtained. The yields were about $99 \%$ based on phosphorus and no elements other than phosphorus were detected in the isolated products by energy dispersive X-ray analysis. The colors of the two resulting products were quite similar and differ significantly from that of amorphous red phosphorus. Powder X-ray diffraction showed that the reaction products were amorphous. Structural information on $\mathbf{1}$ and $\mathbf{2}$ was obtained by high-resolution transmission electron microscopy (HRTEM), see Figure 2. The HRTEM images can be interpreted as showing the parallel orientation
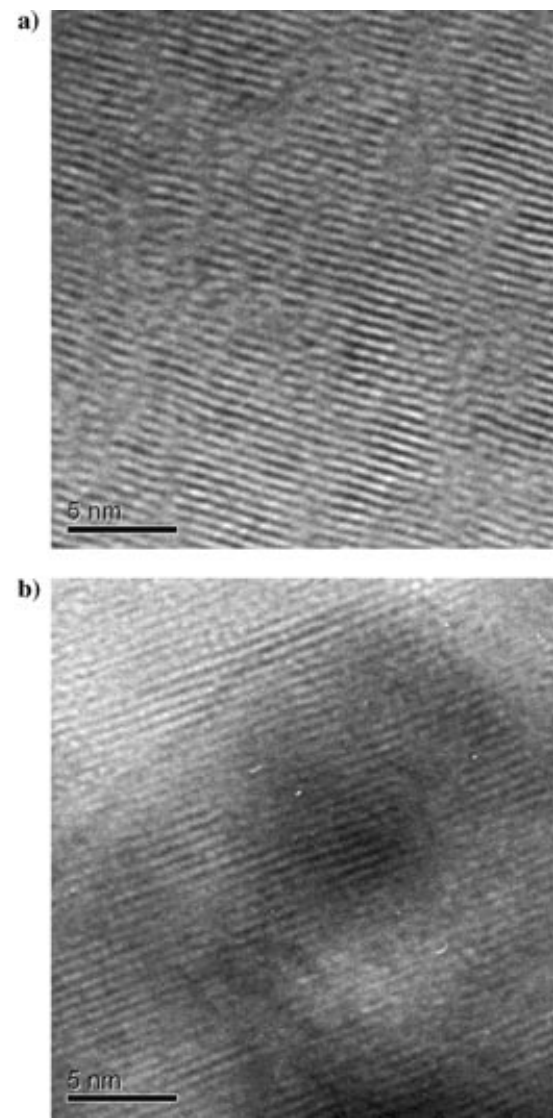

Figure 2. HRTEM images of a) 1 and b) 2. The parallel arrangement of the phosphorus nanorods is clear.

of the isolated phosphorus nanorods over a range of at least $30 \mathrm{~nm}$. However, the stacking periods of the rods can be determined by means of line scans perpendicular to the polymers. Thus, we obtained a period of $5.0 \AA$ for $\mathbf{1}$ and of $5.4 \AA$ for 2 . The diameters present in the crystalline $\mathrm{CuI}$ adducts are $3.3 \AA$ (1) and $4.7 \AA$ (2). To obtain structural information on a local level, ${ }^{31} \mathrm{P}$ MAS NMR spectra (MAS is magic angle spinning) of the crystalline starting materials and of the amorphous phosphorus allotropes derived from these starting materials were recorded (Figure 3 ). The parent compounds $(\mathrm{CuI})_{8} \mathrm{P}_{12}$ and $(\mathrm{CuI})_{3} \mathrm{P}_{12}$ are easily distinguished, thus reflecting the differences in the local environments of the 12 distinct phosphorus sites found in each polymer. However, in $(\mathrm{CuI})_{3} \mathrm{P}_{12}$, the situation is a bit more complicated. Due to the packing in the crystal structure, two different polymers are present with a different number of copper atoms coordinating the phosphorus strands. When the metal halide is removed from the compound, both strands become equivalent. One has to assume that the strands show some relaxation, especially of the bond angles, upon extraction of the metal halide from the starting material. Compared to their starting materials, the spectra of $\mathbf{1}$ and $\mathbf{2}$ are significantly broadened, thus reflecting the loss of long-range periodicity in these amorphous samples. However, the spectra obtained for $\mathbf{1}$ and 2 differ from each other, each exhibiting principally the shape of the signal envelope of its respective starting material. These results suggest that the individual nanorods remain 

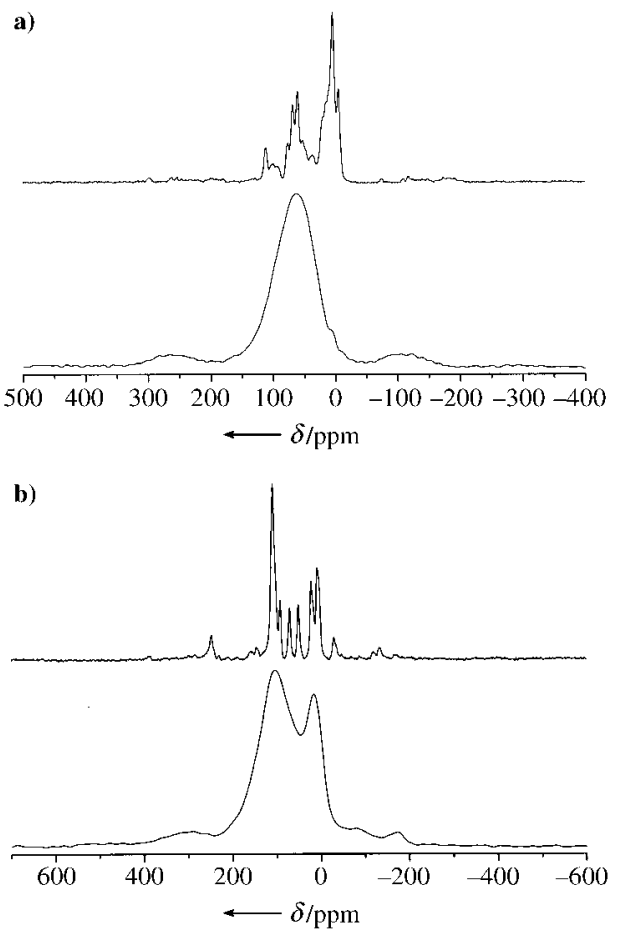

Figure 3. a) $162.05 \mathrm{MHz}^{31} \mathrm{P}$ MASNMR spectra of $(\mathrm{Cul})_{3} \mathrm{P}_{12}$ (top) and 2 (bottom), at a rotor speed of $30 \mathrm{kHz}$; b) ${ }^{31} \mathrm{P}$ MAS NMR spectra of (Cul) ${ }_{8} \mathrm{P}_{12}$ recorded at $202.46 \mathrm{MHz}$ at a rotor speed of $28 \mathrm{kHz}$ (top), and 1 , recorded at $81.01 \mathrm{MHz}$ at a rotor speed of $15 \mathrm{kHz}$ (bottom)

unchanged when they are extracted from the adducts by an aqueous cyanide solution. Due to the existence of two crystallographically different strands in $(\mathrm{CuI})_{3} \mathrm{P}_{12}$ that become equivalent in the pure element, it is quite reasonable that the NMR spectra of $(\mathrm{CuI})_{3} \mathrm{P}_{12}$ and of $\mathbf{2}$ are not as closely related as those of $(\mathrm{CuI})_{8} \mathrm{P}_{12}$ and $\mathbf{1}$.

We conclude that copper(I) halides can be used as an synthetic tool, ${ }^{[6]}$ not only for the synthesis of unknown molecules and polymers, but also for the phosphorus polymers ${ }_{\infty}^{1}[\mathrm{P} 8] \mathrm{P} 4(4)\left[\right.$ and ${ }_{\infty}^{1}[\mathrm{P} 10] \mathrm{P} 2[$, which can readily be extracted from the adduct compounds. By following this approach, two novel allotropic modifications of this long known element are established. Further investigations dealing with the chemical and physical characterization of these polymers as well as the isolation of the $[\mathrm{P} 12(4)] \mathrm{P} 2[$ nanorod are in progress.

\section{Experimental Section}

The starting materials $(\mathrm{CuI})_{8} \mathrm{P}_{12}$ and $(\mathrm{CuI})_{3} \mathrm{P}_{12}$ were obtained by treating stoichiometric mixtures of $\mathrm{CuI}(>98 \%$, Merck) with red phosphorus $\left(99.999 \%\right.$, Hoechst) as formerly described. ${ }^{[13,16]} \mathrm{CuI}$ was purified by recrystallization from aqueous HI prior to use. ${ }^{[6]}$ The purity of the adduct compounds was checked by X-ray powder diffraction (STOE STADI P, Ge monochromator, $\mathrm{Cu}_{\mathrm{K} \alpha 1}$ ). Pure $(\mathrm{CuI})_{8} \mathrm{P}_{12}$ or $(\mathrm{CuI})_{3} \mathrm{P}_{12}(1$ to $5 \mathrm{~g})$ was dissolved in a $1 \mathrm{molL}^{-1}$ aqueous solution of $\mathrm{KCN}$ under an atmosphere of nitrogen. The reaction mixtures were stirred for three days at room temperature. The darkred/brown residue was isolated by filtration under an inert atmosphere and subsequently dried by washing with aqueous $\mathrm{KCN}$ and water. After the products had been dried in a vacuum, a yield of about
$99 \%$ based on phosphorus was obtained in both cases. By means of chemical analyses the corresponding amounts of copper (nearly $100 \%$ in each case) were determined in the aqueous solution. This means the extraction process is quantitative and only traces are lost during the isolation process. The pure and dry phosphorus nanorods are fairly air-stable over a period of several weeks. However, the chemical reactivity of the phosphorus nanorods under discussion has to be elucidated in future experiments. Solid-state NMR spectroscopy measurements were conducted on Bruker DSX-400 and 500 spectrometers equipped with high-speed MASNMR probes. Spectra were recorded with rotor-synchronized spin echoes and relaxation delays ranging from 60 to 300 seconds. $(\mathrm{CuI}){ }_{8} \mathrm{P}_{12}:{ }^{31} \mathrm{P}$ NMR $(202.44 \mathrm{MHz}$, $\left.85 \% \mathrm{H}_{3} \mathrm{PO}_{4}\right): \delta=109.0,102.8,92.0,20.7,50.4,21.7,16.5,8.0,3.3 \mathrm{ppm}$. $(\mathrm{CuI})_{3} \mathrm{P}_{12}:{ }^{31} \mathrm{P}$ NMR $\left(162.05 \mathrm{MHz}, 85 \% \mathrm{H}_{3} \mathrm{PO}_{4}\right): \delta=112.1,102.8$, 99.5, 68.4, 60.4, 52.7, 47.0, 37.1, 20.3, 14.8, 4.4, -5.3 ppm. 1: ${ }^{31} \mathrm{P}$ NMR $\left(81.01 \mathrm{MHz}, \quad 85 \% \quad \mathrm{H}_{3} \mathrm{PO}_{4}\right): \quad \delta=101, \quad 15 \mathrm{ppm} . \quad 2: \quad{ }^{31} \mathrm{P}$ NMR $\left(162.05 \mathrm{MHz}, 85 \% \mathrm{H}_{3} \mathrm{PO}_{4}\right): \delta=65 \mathrm{ppm}$.

A more detailed investigation of different phosphorus polymorphs, especially red phosphorus from different sources, is in progress to provide more detailed structural information and the influence of the preparation techniques on the molecular structure.

For the HRTEM measurements, the powdery materials were suspended in distilled water and small amounts of the suspension were transferred onto a specimen microgrid, which has previously been coated with a thin electron-transparent carbon film. The investigations were carried out on particles protruding over the edge of holes in the carbon film, thus ensuring that no additional phase blur arising from the amorphous film decreased the contrast. The microscope used was a Philips CM 30 equipped with a TWIN objective lens which allows a resolution of $0.23 \mathrm{~nm}$ to be achieved. The microscope was operated at $300 \mathrm{kV}$ for the investigations. During the investigations one could observe a slight tendency of the electron beam to induce structure degradation.

Received: April 6, 2004 [Z460244]

Keywords: element modification - nanorods .

NMR spectroscopy · phosphorus

[1] For example: D. E. C. Corbridge, Phosphorus 2000, Elsevier, Amsterdam, 2000.

[2] A. Simon, H. Borrmann, J. Horakh, Chem. Ber. 1997, 130, 1235.

[3] H. Thurn, H. Krebs, Acta Crystallogr. Sect. B 1969, 25, 125.

[4] R. Hultgren, N. S. Gingrich, B. E. Warren, J. Chem. Phys. 1935, 3, 351.

[5] S. Böcker, M. Häser, Z. Anorg. Allg. Chem. 1995, 621, 258.

[6] A. Pfitzner, Chem. Eur. J. 2000, 6, 1891.

[7] A. Pfitzner, S. Reiser, T. Nilges, Angew. Chem. 2000, 112, 4328; Angew. Chem. Int. Ed. 2000, 39, 4160.

[8] S. Reiser, G. Brunklaus, J. H. Hong, J. C. C. Chan, H. Eckert, A. Pfitzner, Chem. Eur. J. 2002, 8, 4228.

[9] T. Nilges, S. Reiser, A. Pfitzner, Z. Anorg. Allg. Chem. 2003, 629, 563.

[10] G. Brunklaus, J. C. C. Chan, H. Eckert, S. Reiser, T. Nilges, A. Pfitzner, Phys. Chem. Chem. Phys. 2003, 5, 3768.

[11] S. Nilges, T. Nilges, H. Haeuseler, A. Pfitzner, J. Mol. Struc. 2004, in press.

[12] M. H. Möller, W. J. Jeitschko, J. Solid State Chem. 1986, 65, 178.

[13] A. Pfitzner, E. Freudenthaler, Angew. Chem. 1995, 107, 1784; Angew. Chem. Int. Ed. Engl. 1995, 34, 1647.

[14] A. Pfitzner, E. Freudenthaler, Z. Naturforsch. B 1997, 52, 199.

[15] The nomenclature used here was developed by Häser et al., for example [5]. The advantage is that this systematic description of phosphorus molecules enables the user to describe such structures in terms of small fragments or cages, which are combined to form bigger molecular units. In case of the polymers 
$\mathbf{1}$ and $\mathbf{2}$, the advantage becomes immediately obvious: both have $\mathrm{P}_{12}$ as repeating units. Compound $\mathbf{1}$ consists of $\mathrm{P}_{8}$ cages connected by $\mathrm{P}_{4}$ rings- ${ }_{\infty}^{1}[\mathrm{P} 8] \mathrm{P} 4(4)\left[-\right.$, and 2 exhibits $\mathrm{P}_{10}$ cages which are linked by $\mathrm{P}_{2}$ fragments- ${ }_{\infty}^{1}[\mathrm{P} 10] \mathrm{P} 2[$.

[16] E. Freudenthaler, A. Pfitzner, D. C. Sinclair, Mater. Res. Bull. 1996, 31(2), 171. 